www.jmscr.igmpublication.org

Index Copernicus Value: 79.54

ISSN (e)-2347-176x ISSN (p) 2455-0450

crossref DOI: https://dx.doi.org/10.18535/jmscr/v7i4.166

Journal Of Medical Science And Clinical Research

\title{
To Study the Comparative yield of Zn Staining v/s CBNAAT (Gene Xpert) in Clinically Diagnosed cases of Tubercular Pleural Effusion
}

Authors

\section{Jain $\mathbf{G}^{1}$, Jain $\mathrm{VK}^{2}$, Mishra $\mathrm{M}^{3}$, Maan $\mathrm{L}^{4}, \operatorname{Garg} \mathrm{A}^{5}$, Bhardwaj $\mathbf{G}^{6}$}

${ }^{1,5}$ Resident, Department of Respiratory Medicine, Mahatma Gandhi MedicalCollege \& Hospital, Jaipur, Rajasthan

${ }^{2}$ Professor and HOD, Department of Respiratory Medicine, Mahatma Gandhi Medical College \& Hospital, Jaipur, Rajasthan

${ }^{3}$ Professor, Department of Respiratory Medicine, Mahatma Gandhi Medical College \& Hospital, Jaipur, Rajasthan

${ }^{4}$ Assistant Professor, Department of Respiratory Medicine, Mahatma Gandhi Medical College \& Hospital, Jaipur, Rajasthan

${ }^{6}$ Assistant Professor, Department of TB \& Chest, RUHS-CMS, Jaipur, Rajasthan

${ }^{4}$ Corresponding Author

Dr Lokesh Maan

Assistant Professor, Department of Respiratory Medicine, Mahatma Gandhi Medical College \& Hospital, Jaipur (Rajasthan) 302022, India

Email: drlokeshmaan@gmail.com, Contact no- 08875547660

\begin{abstract}
Background: India accounts for a quarter of global TB burden in which 15-20\% are extra-pulmonary TB. Tubercular pleural effusion is the most common extra pulmonary TB after Tubercular lymphadenitis. Tubercular effusion remains mostly undiagnosed due to pauci-bacillary nature. Early detection of Tuberculosis and Drug Resistance is the priority in diagnosis for early disease management and reduce morbidity. Molecular biological tests specially CBNAAT is one of the important method for early and rapid diagnosis of mycobacterium tuberculosis in specimen/tissue having pauci-bacillary nature with good sensitivity and specificity.

Materials and Methods: This is a retrospective study conducted in Department of Respiratory Medicine, MGMCH Jaipur in 150 patients of clinically diagnosed cases of tubercular pleural effusion between August 2016 to July 2018. In addition to detailed clinical history/examination and radio imagine Pleural fluid for routine Biochemical examination reports evaluated for protein, sugar ADA and cell cytology, suspecting tubercular in nature were taken in our study. In all these cases AFB by ZN staining and CBNAAT done and comparative reports evaluated.

Results: A total of 150 cases of clinically diagnosed tubercular pleural effusion, MTB was Detected by ZN staining in 11(7.33\%) and CBNAAT in 38(25.33\%) cases. CBNAAT yield was significantly more as compare with ZN Staining. Among 38 cases who were positive for CBNAAT only 11 cases were positive for ZN Staining showing poor yield of ZN Staining.

Conclusion: CBNAAT is newly emerging and highly sensitive and specific technique for early and rapid diagnosis of Tubercular Pleural effusion including resistant pattern of Rifampicin in view of MDR as compared to ZN staining.
\end{abstract}

Keywords: $M T B, C B N A A T, Z N$ staining, $M D R, A D A$. 


\section{Background}

TB is a major health problem worldwide caused by the bacillus Mycobacterium tuberculosis infection. It commonly affects the lungs (pulmonary TB) but can also affect any other organ (extra-pulmonary TB). ${ }^{1}$ Overall, a relatively small proportion $(5-15 \%)$ of the estimated 1.7 billion people infected with $\mathrm{M}$. tuberculosis will develop TB disease during their lifetime. However, the probability of developing TB disease is much higher among people infected with HIV, and also higher among people affected by risk factors such as under-nutrition, diabetes, smoking and alcohol consumption. As per the Global TB report 2017 the estimated incidence of TB in India was approximately 2.8 million accounting for about a quarter of the world TB cases. $^{2}$

Pleural TB is the second most common extrapulmonary manifestation after lymph node TB worldwide. $^{3}$ The clinical presentation of extrapulmonary tuberculosis is atypical because of pauci-bacillary nature of extra-pulmonary specimen and often remain either undiagnosed or misdiagnosed due to lack of diagnostic tools. ${ }^{4}$ Diagnosis of pleural TB relies on the examination of pleural fluid and/or biopsy specimens using acid-fast microscopic examination, culture, polymerase chain reaction, evaluation of pleural fluid characteristics, and/or histo-pathological examination. ${ }^{5}$ The World Health Organization (WHO) has endorsed the implementation of GeneXpert MTB/RIF assay for the national tuberculosis programs in developing countries in 2013 . $^{6}$

Gene Xpert MTB/RIF is an automated, user friendly and rapid based on nested real-time PCR assay and molecular beacon technology for MTB detection and RIF resistance. The results were obtained within a short period of 2 hours. It is a highly specific test as it uses 3 specific primer and 5 unique molecular probes to target RpoB gene of mycobacterium tuberculosis (MTB). This technique is not prone to cross contamination, requires minimal Biosafety facilities and has a high sensitivity in smear negative pleural TB. ${ }^{7}$

This study was aimed to evaluate the value of GeneXpert MTB/RIF Assay as an rapid and accurate diagnosis of clinically diagnosed pleural tuberculosis cases and also compareits value with $\mathrm{ZN}$ staining for Acid fast bacilli in pleural fluid.

\section{Materials and Methods}

Our hospital is located at Jaipur in Rajasthan state which cater both urban and rural population from all over state even other adjoining states. It is also a referral center for higher medical services. This is a retrospective study conducted in Department of Respiratory Medicine, MGMCH Jaipur in 150 clinically diagnosed cases of tubercular pleural effusion between August 2016 to July 2018. In addition to detailed clinical history/examination and radio imagine Pleural fluid for routine Biochemical examination reports evaluated for protein, sugar ADA and cell cytology, suspecting tubercular in nature were taken in our study. In all these cases AFB by $\mathrm{ZN}$ staining and CBNAAT done and comparative reports evaluated.

\section{Inclusion criteria}

- Patient having clinical feature and radioimagine suggestive of Pleural Effusion

Exudative nature of pleural fluid

- Lymphocytic predominance

- $\mathrm{ADA}>40$ unit/Liter

- Protein $>3 \mathrm{gm} / \mathrm{dl}$

- Patient age $>15$ year age

- Patient/relative given informed written consent for study

\section{Exclusion criteria}

- Transudative Pleural Effusion

- Patients with Heart \& Renal failure, Nephrotic syndrome, Liver cirrhosis

- Contraindication of thoracocentesis like serious condition, uncooperative, bleeding diathesis \& patient on anticoagulant therapy

- Patient age $<15$ Year

- Patient/relative not giving informed written consent 


\section{Results}

Over the mentioned period of time duration, total no of 150 cases who met the inclusion criteria were evaluated carefully. Out of 150 cases $117(78 \%)$ were males\& $33(22 \%)$ were females (Table no. 1). Majority of cases $88(58.67 \%)$ belong to less than 45 years of age (Table no. 2). Most of the cases belonged to rural background $101(67.33 \%)$ and $49(32.67 \%)$ from urban (Table no. 3).

Fever is the most common presenting symptom followed by chest pain, dyspnea Cough\& weight loss (Table no. 4). Most of the pleural effusions are unilateral $(94.67 \%)$ in which right side involvement $94(62.67 \%)$ cases and left side $48(32 \%)$ cases while bilateral in $8(5.33 \%)$ cases (Table no. 5).

ZN Staining for Acid Fast Bacilli \& CBNAAT for Mycobacterium Tuberculosis done for in all 150 cases in which $11(7.33 \%)$ cases shows $\mathrm{ZN}$ Staining positivity \& 38(25.33\%) cases shows CBNAAT positivity (Table no. $6 \& 7$ ). All 11 cases who were ZN Staining positive shows CBNAAT for MTB Positivity (Table no. 8). Out of 38 CBNAAT positive cases Rifampicin Resistance were detected in only $6(15.79 \%)$ cases (Table no. 9).

Table 1 Gender profile

\begin{tabular}{|l|c|c|}
\hline Gender & No. of cases & Percentage \\
\hline Male & 117 & 78 \\
\hline Female & 33 & 22 \\
\hline Total & $150(100 \%)$ & 100 \\
\hline
\end{tabular}

Table 2 Age profile

\begin{tabular}{|l|c|c|}
\hline Age group & No. of cases & Percentage \\
\hline $18-29$ & 45 & 30 \\
\hline $30-44$ & 43 & 28.67 \\
\hline $45-59$ & 34 & 22.67 \\
\hline$>60$ & 28 & 18.66 \\
\hline Total & 150 & 100 \\
\hline
\end{tabular}

Table 3 Distribution of cases according to residence (Urban/Rural)

\begin{tabular}{|l|c|c|}
\hline Residence & No. of cases & Percentage \\
\hline Rural & 101 & 67.33 \\
\hline Urban & 49 & 32.67 \\
\hline Total & 150 & 100 \\
\hline
\end{tabular}

Table 4 Symptoms profile

\begin{tabular}{|l|c|}
\hline Symptoms & Percentage \\
\hline Fever & 91.33 \\
\hline Chest pain & 82.67 \\
\hline Dyspnea & 56.67 \\
\hline Cough & 52.00 \\
\hline Weight loss & 48.67 \\
\hline
\end{tabular}

Table 5 Radiological involved of chest

\begin{tabular}{|l|c|c|}
\hline Side & No. of cases & Percentage \\
\hline Right & 94 & 62.67 \\
\hline Left & 48 & 32.00 \\
\hline Bilateral & 8 & 5.33 \\
\hline Total & 150 & 100 \\
\hline
\end{tabular}

Table 6.Yield of AFB by ZN staining Technique

\begin{tabular}{|l|c|c|}
\hline ZN Staining & No. of cases & Percentage \\
\hline Positive & 11 & 7.33 \\
\hline Negative & 139 & 92.67 \\
\hline Total & 150 & 100 \\
\hline
\end{tabular}

Table 7 Yield of MTB by Gene XPERT Assay

\begin{tabular}{|l|c|c|}
\hline GeneXpert & No. of cases & Percentage \\
\hline Positive & 38 & 25.33 \\
\hline Negative & 112 & 74.67 \\
\hline Total & 150 & 100 \\
\hline
\end{tabular}

Table 8. Comparative Result of ZN Staining \& Gene XPERT

\begin{tabular}{|l|c|c|c|c|c|}
\hline Gene & \multicolumn{3}{|c|}{ ZN Staining } & Sensitivity & Specificity \\
\cline { 2 - 4 } Xpert & Positive & Negative & Total & $100 \%$ & $86 \%$ \\
\hline Positive & 11 & 27 & 38 & & \\
\hline Negative & - & 112 & 112 & & \\
\hline Total & 11 & 139 & 150 & & \\
\hline
\end{tabular}

Table 9 Profile of Rifampicin resistance by Gene Xpert

\begin{tabular}{|l|c|c|}
\hline Rifampicin resistant & No. of cases & Percentage \\
\hline Detected & 6 & 15.79 \\
\hline Not detected & 32 & 84.21 \\
\hline Total & 38 & 100 \\
\hline
\end{tabular}

\section{Discussion}

Demonstration of tubercular bacilli as well as caseating granuloma are the gold standard for the diagnosis of tuberculosis. ${ }^{8}$ Inspite of all the efforts most of the time it is negative in case of tubercular pleural effusion due to its pauci-bacillary nature and etiology of pleural fluid remain undiagnosed or misdiagnosed. Pleural fluid analysis by cytology, biochemistry and ADA is not always diagnostic, similar picture may be present in some 
other diseases thus, creating diagnostic confusion. ${ }^{9}$

Our study was planned to know the role of Gene Xpert MTB/RIF in the diagnosis of tubercular pleural effusion and rifampicin resistance as not many studies are available in the literature.

Out of 150 cases more than $3 / 4^{\text {th }}$ cases were males similar male predominance were reported by various studies done by Parikh et $\mathrm{al}^{10}$ who reported that $68 \%$ were male, Arya et $\mathrm{al}^{11}$ reported $70 \%$ males.Approx. $3 / 5^{\text {th }}$ cases were belongs to less than 45 years of age similar age group reported by Parikh et al ${ }^{10}$, Arya et al ${ }^{11}$ Ferreiro L et al. ${ }^{12}$ Most of studied cases belonged to rural background $2 / 3$ rd followed by $1 / 3$ rd were from urban background.

Most common symptomfever (91\%) followed by chest pain (87\%), dyspnea (67\%) cough (52\%) \& weight loss (49\%) similar to study J. Ferrer. ${ }^{13}$ Most of the Pleural effusions are Unilateral in which Right side involvement $62.67 \%$ cases followed by left side $32 \%$ cases and bilateral in $5.33 \%$ cases similar to study reported by Valdés L et al. ${ }^{14}$

In present study low Yield $7.33 \%$ cases shows $\mathrm{ZN}$ Staining positivity comparable with study of Mittal \& $\operatorname{Kumar}^{15}(14 \%)$. Gene Xpert positive yield is $25.33 \%$ cases in our study compared with other studies of Ahmed et $\mathrm{al}^{16}(15.8 \%)$, Shukla A et $\mathrm{al}^{17}(20.58 \%)$, Mittal \& $\mathrm{kumar}^{15}$ (35\%), Pravin $\&$ Chourasia $^{18}(32 \%)$.All 11 cases who were ZN Staining positive shows GeneXpert Assay for MTB Positivity. We also evaluated sensitivity and specificity of Gene Xpert in smear positive and smear negative cases which was $100 \%$ sensitive and $86 \%$ specific.Rifampicin resistance were detected in only $15.79 \%$ cases out of 38 GeneXpert Assay positive cases while Pravin \& Chourasia $^{18}$ reported $19 \%$ and Shukla A et al ${ }^{17}$ reported $21 \%$.

\section{Conclusion}

Tubercular Pleural Effusion important cause of morbidity \&mortality,high prevalence in India,so need of rapid diagnostic method for early treatment \& cure to reduce the TB burden. The results of present study show that Gene Xpert MTB/RIF assay could play a significant role as routine diagnostic investigation in ClinicoRadiological \& Biochemical suspected cases of tubercular pleural effusion and advantage of detection of Rifampicin drug resistance tuberculosis, where resources of pleural fluid culture are limited, case burden is high and is time consuming, whereas results of Gene Xpert MTB/RIF are available in same day with acceptable sensitivity and specificity.

\section{Source of support: Nil}

\section{References}

1. Procel JM. Tuberculous pleural effusion. Lung 2009;187:263-70.

2. World Health Organization;2017. Global Tubeculosis Report 2017.

3. TrajmanA et al. Novel tests for diagnosing tuberculosis pleural effusion: What works and what does not? EurRespir J.2008;31:1098-106.

4. Chakravarty S, Sen MK, Tyagi JS (2005) Diagnosis of extra pulmonary tuberculosis by smear, culture, and PCR using universal sample processing technology. J ClinMicrobiol 43(9): 4357-4362.

5. Sahn SA et al. Can tuberculous pleural effusion be diagnosed by pleural fluid analysis alone?Int $\mathrm{J}$ Tuberc Lung Dise. 2013;17:787-93.

6. TB CARE I. International Standards for Tuberculosis Care, 3rd edition. 2014. Available at URL: www.istcweb.org.

7. Boehme CC. "Rapid molecular detection of tuberculosis and rifampin resistance". N Engl J Med.2010; 363:1005-1015.

8. Light RW. Update on tuberculous pleural effusion. Res-pirology,2010;15:451- 8.

9. Koegelenberg CF, Bolliger CT, Theron J etal. Direct comparison of the diagnostic yield of ultrasound assisted Abram and Tru-cut needle biopsies for pleural tuberculosis. Thorax, 2010; 65: $857-62$. 
10. Parikh P, Odhwani J, Ganagajalia C. Study of 100 cases of pleural effusion with reference to diagnostic approach. Int $\mathbf{J} \mathrm{Adv}$ Med 2016;3:328-331.

11. Arya Shashikant et al. A Study of Clincoetiological Profile of Patients with Pleural Effusion. IOSR Journal of Dental and Medical Sciences Jan 2017;16(1):2327

12. Ferreiro L, San José E, Valdés L (2014). "Tuberculous pleural effusion.". Arch Bronconeumol.50(10): 435-43.

13. J. Ferrer. Pleural tuberculosis. EurRespir J.1997;10:942-947

14. Valdés L, Alvarez D, San José E, et al. Tuberculous pleurisy: a study of 254 patients. Arch Intern Med 1998;158:201721.

15. Mahim Mittal, Ritesh Kumar. Int J Res Med Sci.2017;7:2952-2955.

16. Ahmad N S, Sana khan, Aneeqa Shamshad Butt. Rapid detection of Mycobacterium tuberculosis and Rifampicin Resistance in extra pulmonary samples using Gene Xpert MTB/RIF assay. IOSR Journal of Dental and Medical Sciences 11/2014; 13(11):2279- 861.DOI: 10.9790/0853131145053.

17. ShuklaA et al.Role of gene Xpert MTB/ RIF assay in diagnosis of Tubercular Pleural Effusion.Int. J. Curr. Res. Med. Sci. (2017). 3(5): 105-110.

18. Pravin KN and Choursai E, Use of Gene XPERT Assay for Diagnosis of Tuberculosis From Body Fluid Specimens, a 2 Year Study. J Microbiol Biotechnol, 2016, 1(1):000105. 